Western University

Scholarship@Western

4-2009

\title{
Physical Activity Levels of Older Community-dwelling Adults Are Influenced by Summer Weather Variables
}

\author{
Caitlin A. Brandon \\ The University of Western Ontario \\ Dawn P. Gill \\ University of Washington \\ Mark Speechley \\ The University of Western ontario \\ Jason Gilliland \\ The University of Western Ontario \\ Gareth R. Jones \\ University of British Columbia
}

Follow this and additional works at: https://ir.lib.uwo.ca/geographypub

Part of the Epidemiology Commons, Geography Commons, and the Rehabilitation and Therapy

Commons

Citation of this paper:

Brandon, Caitlin A.; Gill, Dawn P.; Speechley, Mark; Gilliland, Jason; and Jones, Gareth R., "Physical Activity Levels of Older Community-dwelling Adults Are Influenced by Summer Weather Variables" (2009).

Geography Publications. 159.

https://ir.lib.uwo.ca/geographypub/159 


\title{
Physical activity levels of older community- dwelling adults are influenced by summer weather variables
}

\author{
Caitlin A. Brandon, Dawn P. Gill, Mark Speechley, Jason Gilliland, and \\ Gareth R. Jones
}

\begin{abstract}
Adequate daily physical activity (PA) is important for maintaining functional capacity and independence in older adults. However, most older adults in Canada do not engage in enough PA to sustain fitness and functional independence. Environmental influences, such as warmer daytime temperatures, may influence PA participation; however, few studies have examined the effect of summertime temperatures on PA levels in older adults. This investigation measured the influence of summertime weather variables on PA in 48 community-dwelling older adults who were randomly recruited from a local seniors' community centre. Each participant wore an accelerometer for a single 7-consecutive-day period (between 30 May and 9 August 2006) during waking hours, and completed a PA logbook to remark on major daily PA events. Local weather variables were collected from a national weather service and compared with PA counts per minute. Regression analysis revealed a curvilinear relationship between log-transformed PA and mean daily temperature $\left(r^{2}=\right.$ $0.025 ; p<0.05)$. Linear mixed effects models that accounted for repeated measures nested within individuals were performed for monthly periods, meteorological variables, sex, age, and estimated maximal oxygen consumption, with PA as the dependent variable. Age and Air Quality Index remained significant variables within the model. Higher fitness levels had no effect on allowing individuals to perform more vigorous PA in warmer temperatures.
\end{abstract}

Key words: seniors, accelerometry, meteorology, fitness.

Résumé : Il importe pour les personnes âgées de pratiquer une quantité suffisante d'activité physique afin de maintenir leur capacité fonctionnelle et leur autonomie, et ce, tous les jours. Actuellement, la majorité des adultes au Canada ne font pas assez d'activité physique pour se maintenir en forme et garder leur autonomie fonctionnelle. Il semble que des facteurs environnementaux, notamment du temps plus chaud durant le jour, puissent avoir un effet sur la pratique de l'activité physique. Il y a cependant peu d'études sur l'effet de la température estivale sur le degré de pratique de l'activité physique chez les personnes âgées. Cette étude se propose d'analyser l'effet de variables météorologiques estivales sur le degré de pratique de l'activité physique chez 48 personnes âgées sollicitées aléatoirement dans un centre communautaire de personnes âgées. Durant ses heures d'éveil, chaque participant porte un accéléromètre au cours d'une seule période consécutive de sept jours (entre le 30 mai et le 9 août 2006) et consigne dans un carnet de notes ses principales activités physiques de la journée. On note les valeurs des variables météorologiques fournies par un organisme national de météo et on les met en relation avec le nombre de pas par minute affiché par l'accéléromètre. L'analyse de régression révèle une relation curvilinéaire entre le logarithme des données d'activité physique et la température moyenne de la journée $\left(r^{2}=0,025, p<\right.$ 0,05). Aux variables indépendantes (mois, valeurs météorologiques, sexe, âge, consommation d'oxygene maximale prédit), on applique des modèles linéaires aux effets mixes qui prennent en compte les mesures répétées chez les mêmes individus pour prédire la valeur de la variable dépendante, soit la pratique de l'activité physique. Dans ce modèle, l'âge et l'indice de la qualité de l'air sont des variables signifiantes. Les personnes présentant une meilleure condition physique ne pratiquent pas des activités physiques plus intenses par temps plus chaud.

Mots-clés : personnes âgées, accéléromètre, météorologie, condition physique.

[Traduit par la Rédaction]

Received 29 August 2008. Accepted 12 January 2009. Published on the NRC Research Press Web site at apnm.nrc.ca on 1 April 2009.

C.A. Brandon. Brandon, Health and Rehabilitation Sciences, University of Western Ontario, Elborn College, London, ON N6G 1H1, Canada.

D.P. Gill. National Alzheimer's Coordinating Center, Department of Epidemiology, University of Washington, Seattle, WA 98105, USA. M. Speechley. Department of Epidemiology and Biostatistics, Schulich School of Medicine and Dentistry, University of Western Ontario, London, ON N6A 5C1, Canada.

J. Gilliland. Department of Geography, Faculty of Social Sciences, University of Western Ontario, London, ON N6A 5C2, Canada. G.R. Jones. ${ }^{1}$ Human Kinetics - Faculty of Health and Social Development, University of British Columbia-Okanagan, Kelowna, BC V1V 1V7, Canada.

${ }^{1}$ Corresponding author (e-mail: gareth.jones@ubc.ca). 


\section{Introduction}

A wealth of epidemiological evidence confirms that physical activity (PA) substantially reduces the impact of age-related morbidity and mortality in older adults (Pedersen and Saltin 2006). Current national initiatives and recommendations encourage older adults to engage in moderate to vigorous PA for 30-60 min on most days of the week to maintain health, fitness, and ultimately functional independence (Health Canada 1999; Paterson et al. 2007). Unfortunately, more than half of older Canadians currently do not meet these PA recommendations (NACA 2006).

Recent evidence suggests that weather conditions and seasonality may influence the PA participation of adults (Chan et al. 2006; Merrill et al. 2005; Pivarnik et al. 2003; Tucker and Gilliland 2007), and older adults in particular (Togo et al. 2005; Tu et al. 2004; Yasunaga et al. 2008). Weather conditions and seasonality also impact health-related variables, such as fracture risk (Bischoff-Ferrari et al. 2007; Mirchandani et al. 2005), food intake (Ma et al. 2006), blood cholesterol (Matthews et al. 2001), and asthma (Mancuso et al. 2006). No investigation to date has focused specifically on the influence of summertime temperatures on daily PA participation levels in older adults ( $\geq 70$ years of age).

Annual summertime temperatures have increased gradually since 1948, with an overall warming trend of approximately $0.9{ }^{\circ} \mathrm{C}$ (Environment Canada 2007). Extreme summertime temperatures are responsible for increased mortality in older adults (Diaz et al. 2002; O'Neill et al. 2005; Smoyer et al. 2000), especially in regions unaccustomed to extreme temperature fluctuations (Hechler et al. 2004). Generally, older adults have difficulty regulating body temperature (Anderson et al. 1996; Nakamura et al. 1997; Potkanowicz et al. 2003; Scremin and Kenney 2004; Worfolk 1997), as a result of age-associated detuning of the autonomic regulatory system (Collins et al. 1980). Autonomic detuning is responsible for decreased peripheral vasodilation in response to thermal stress (Richardson and Shepherd 1991), reduced sweating (Foster et al. 1976) and inducing a greater variance in control of core body temperature (Marion et al. 1989). Men have a better sweating response than women, owing to increased body and muscle mass (Anderson et al. 1995). However, the sweating response deteriorates with age for both sexes, a result of local skin changes rather than central thermoregulatory alterations (Dufour and Candas 2007). Fitter individuals have more efficient thermoregulatory systems (Bittel et al. 1988; Ho et al. 1997) as a result of improved vascular tone (Westhoff et al. 2007) and improved autonomic cardiovascular functioning (Gulli et al. 2003), and are likely more capable of coping with rising ambient temperatures. To our knowledge, no investigation has yet examined the influence of summer weather variables and fitness on PA participation in older adults.

The purpose of this study was to investigate the relationship between outdoor summer weather variables, including ambient temperature, humidex, and Air Quality Index on daily PA accumulation by healthy community-dwelling older adults. The secondary purpose was to examine whether fitness (estimated by maximal oxygen consumption $\left.\left(V \mathrm{O}_{2 \max }\right)\right)$ has an effect on preserving normal PA accumulation, despite the potential influence of higher ambient tem- peratures, greater humidity, and poor air quality. We hypothesized that daily PA would be negatively influenced by rising daytime temperatures, and that fitter individuals would continue to be physically active despite warmer summer temperatures.

\section{Materials and methods}

The current membership list $(n=370)$ from a local olderadult exercise centre was used to establish a convenience sample population. Participants were excluded if they were $<70$ years of age. A total of 203 participants remained and were randomly selected, using a random numbers table, to generate a contact list. Participants were initially contacted by an exercise centre staff member, who obtained the participant's verbal consent to attend a baseline assessment. At the baseline assessment, the study protocol was explained and written consent was obtained. It was estimated that 46 people were sufficient to have $80 \%$ power to detect a correlation coefficient of 0.4 or larger, as per the method described by Walter and colleagues (1998). A total of 109 individuals were contacted, of which 58 declined to attend an assessment session. Reasons for refusals included illness or recovering from illness $(n=18)$, lack of interest $(n=12)$, too busy $(n=11)$, away on holiday $(n=11)$, or an ill spouse $(n=4)$. A total of 51 individuals (37 females, 14 males) consented to participate. This study was approved by the Research Ethics Board for Health Sciences Research Involving Human Subjects at the University of Western Ontario.

The initial assessment took approximately $20 \mathrm{~min}$, and required participants to complete a personal health questionnaire, followed by instruction on how to use an accelerometer (ActiGraph GT1M, ActiGraph, Pensacola, Fla.) and how to accurately complete a daily PA logbook. The accelerometer recorded movement counts over a 1-min epoch. These movements were summed to give a value of counts per minute; converted to metabolic equivalent (MET) values using the conversion equation proposed by Freedson and colleagues (1998); and assigned an intensity value (Table 1).

Each participant wore the ActiGraph GT1M accelerometer $(3 \mathrm{~cm} \times 4 \mathrm{~cm} \times 1 \mathrm{~cm} ; 27 \mathrm{~g})$ on their waist for 1 week ( 7 consecutive days) between 30 May and 9 August 2006. Participants were assigned to their study week on the basis of their scheduling availability, typically 1 to 2 weeks in advance. Accelerometer start times were preprogrammed by the investigator. The accelerometer was worn only during waking hours, and participants were instructed to remove it when doing any water-based activities (e.g., bathing, swimming) and when sleeping, including daytime napping. Participants were instructed to wear the accelerometer on the mid-axillary position, over their dominant leg (Ward et al. 2005). The accelerometer was attached to an elastic waistband and could be worn over or under clothing. Since the accelerometer was not worn every minute over the 7-day assessment period, analysis was completed on both raw data (all data regardless of accelerometer removal) and cleaned data (removal of data when accelerometer was not worn, for example when bathing, swimming, or sleeping). Raw data included 0 counts, which give an underestimation of true hourly average PA. Cleaned data consisted of hourly PA averages calculated using only the minutes when partic- 
Table 1. Conversion of accelerometer counts to metabolic equivalents (METs).

\begin{tabular}{lll}
\hline $\begin{array}{l}\text { ActiGraph activity counts, } \\
\text { counts· } \text { min }^{-1}\end{array}$ & METs* & Intensity \\
\hline $0-3250$ & $1-3.99$ & Light \\
$3250-3850$ & $4.0-4.49$ & Moderate \\
$3850-5750$ & $4.5-5.99$ & Moderately vigorous \\
$5750-9000$ & $6.0+$ & Vigorous \\
\hline
\end{tabular}

*1 MET is equivalent to a metabolic rate consuming $3.5 \mathrm{~mL} \cdot \mathrm{kg}^{-1} \cdot \mathrm{min}^{-1}$ of oxygen per kilogram of body mass per minute (American College of Sports Medicine 2006). Conversion equation from ActiGraph activity counts to MET established by Freedson and colleagues (1998).

'Intensity conversions established by Lee and Paffenbarger (2000).

ipants were wearing the accelerometer (as determined by participant logbooks). Eliminating 0 counts when the accelerometer was not worn improves the estimation of the true hourly mean PA. Accelerometer counts $\cdot \min ^{-1}$ were averaged for each hour during the sampling period (average hourly counts. $\mathrm{min}^{-1}$ ) for comparison to the summer weather variables, which were reported hourly (Environment Canada 2006).

Anthropometric and fitness measurements were recorded from fitness appraisal data collected by the same certified fitness assessor employed by the older adult exercise centre. Height and mass measurements were recorded, and estimated $\mathrm{VO}_{2}$ max was determined using a submaximal aerobic step test for older adults (Petrella et al. 2001). Estimated $V \mathrm{O}_{2 \text { max }}$ data were available for 40 individuals (29 females, 11 males) within the sample group. Correlation coefficients were 0.93 (females) and 0.91 (males), where the predictive model explained $72 \%-86 \%$ of variance in $\mathrm{VO}_{2}$ max with standard error of the mean (SEE) of $9 \%-15 \%$ for the step test. For analyses, estimated $V_{2}$ max scores were categorized into 3 groups of equal size (tertiles). These tertiles separated participants into groups based on aerobic fitness level (poor, moderate, and high).

Logbooks were used by participants to report significant PA events (e.g., attending exercise class, going for a walk, heavy gardening) and to record the times they put on and took off the accelerometer. Participants returned the accelerometer along with the PA logbook at the follow-up assessment, within $48 \mathrm{~h}$ of the last accelerometer day. PA data were verified manually against the PA logbooks. Start and stop times were determined in reference to what was reported in the participant logbook. If participants failed to indicate a start and (or) stop time, visual inspection of minuteby-minute accelerometer counts was conducted to determine start and stop times for the sampling day. This was deemed to be valid as the first spike of activity during the day was clearly evident in the accelerometer output.

Meteorological data were collected daily. The data were retrieved online from Environment Canada records measured at the London International Airport (latitude $43^{\circ} 2^{\prime} \mathrm{N}$ ) (Environment Canada 2006). Variables recorded hourly included ambient temperature, percent humidity, humidex, and Air Quality Index.

Statistical analysis was performed using SPSS 14.0 (SPSS Inc., Chicago, Ill.) and SAS 9.1 (SAS Institute Inc., Cary, N.C.). The first step was visual inspection of the raw data, followed by data cleaning. Specifically, erroneous 0 counts, when participants were, in fact, not wearing the accelerome- ter, were deleted. Because of a non-normal distribution, the PA variable (accelerometer counts) was log-transformed. The log-transformed values were normally distributed and, as a result, this form of the variable was used in the regression models. Linear mixed effects models that accounted for repeated measures nested within individuals were performed for monthly periods, meteorological variables, sex, age, and estimated $V \mathrm{O}_{2}$ max , with PA as the dependent variable.

\section{Results}

Fifty-one older adults provided informed consent and began the study. Two subjects, both male, dropped out midweek. One subject withdrew from the study because his spouse felt that he could not complete the PA logbook appropriately, while the other subject had to leave the country unexpectedly. There was 1 accelerometer malfunction in which no data were collected (registered only 0 counts for entire week). The remaining 48 subjects (36 female) wore the accelerometer for 7 consecutive days without malfunction.

Table 2 describes the physical and health characteristics of the sample group. The mean estimated $V \mathrm{O}_{2} \max$ scores suggest that the majority of subjects had satisfactory cardiorespiratory fitness for their age. According to the body mass index (BMI) values, 2\% of the sample were considered underweight, $33.3 \%$ were normal weight, $47.9 \%$ were overweight, $14.6 \%$ were class I obese, and $2 \%$ were class II obese (WHO 2000). Recent evidence suggests that in adults, high BMI scores (above those considered healthy) have a lower relative risk of all cause mortality, compared with younger adult cohorts (Heiat et al. 2001). Seventy percent of participants rated their own health as very good or better. Thirty percent felt they were more active than others the same age. No participant described their memory as being worse than that of others the same age. Most were married or widowed $(85 \%)$, had a postsecondary education $(74 \%)$, and were financially stable.

Accelerometers were worn an average of $4410.5 \pm$ $362.7 \mathrm{~min}$ of a possible $5040 \mathrm{~min}(87.5 \%)$. Two subjects forgot to wear the accelerometer, accounting for 2 missed days. Missing data were not imput for those days. Subjects spent an average of $4380.0 \pm 346.5 \mathrm{~min}$ performing light $\mathrm{PA}, 13.5 \pm 20.6 \mathrm{~min}$ performing moderate PA, 16.5 \pm 44.5 min performing moderately vigorous $\mathrm{PA}$, and only $0.5 \pm 1.9$ min performing vigorous PA (Freedson et al. 1998; Lee and Paffenbarger 2000). These values indicate that this group of older adults recorded an average of $30.5 \mathrm{~min}$ per week at an intensity equivalent to or higher than 4 METs (moderate to vigorous intensity).

A range of PA types were recorded in participant logbooks. However, participants did not reliably record daily PA in sufficient detail to give an accurate representation of PA duration or location (outdoors or indoors). Therefore, logbooks acted as a guide to establish when participants began wearing the accelerometer in the morning, and when they removed it for sleeping or water-based activities.

PA was averaged for each individual for each hour they wore the accelerometer (average hourly counts $\cdot \mathrm{min}^{-1}$ ). Examination of the scatter plot of PA values showed a nonnormal distribution. Given that a normal distribution is required for regression analysis, the accelerometer counts 
Table 2. Characteristics of summer sample subjects $(n=48)$.

\begin{tabular}{|c|c|c|}
\hline Characteristic & Value & Range \\
\hline Age $(\mathrm{y} \pm \mathrm{SD})$ & $77.4 \pm 4.7$ & $71-89$ \\
\hline Weight $(\mathrm{kg} \pm \mathrm{SD})$ & $70.5 \pm 12.0$ & $43.5-103.0$ \\
\hline Height $(\mathrm{m} \pm \mathrm{SD})$ & $1.6 \pm 8.3$ & $1.5-1.9$ \\
\hline Waist-to-hip ratio $( \pm \mathrm{SD})$ & $0.85 \pm 0.09$ & $0.65-1.05$ \\
\hline Female $(n \pm \mathrm{SD})$ & $0.81 \pm 0.07$ & $0.65-0.97$ \\
\hline Male $(n \pm \mathrm{SD})$ & $0.96 \pm 0.06$ & $0.88-1.05$ \\
\hline Body mass index $\left(\mathrm{kg} \cdot \mathrm{m}^{-2}\right)$ & $26.2 \pm 4.0$ & $17.2-37.6$ \\
\hline Estimated $V \mathrm{O}_{2 \max }\left(\mathrm{mL} \cdot \mathrm{kg}^{-1} \cdot \mathrm{min}^{-1}\right)$ & $30.0 \pm 7.6$ & $17.5-45.8$ \\
\hline \multicolumn{3}{|l|}{ Self-perceived health status (\%) } \\
\hline Excellent & 16.7 & \\
\hline Very good & 54.2 & \\
\hline Good & 27.1 & \\
\hline Fair & 2.1 & \\
\hline \multicolumn{3}{|l|}{ Self-perceived weekly activity level (\%) } \\
\hline Vigorously active 3 times per week & 64.6 & \\
\hline Moderately active 3 times per week & 35.4 & \\
\hline \multicolumn{3}{|c|}{ Activity level compared with others the same age $(\%)$} \\
\hline Much more active & 29.2 & \\
\hline About as active & 56.3 & \\
\hline Less active & 14.6 & \\
\hline \multicolumn{3}{|l|}{ Memory compared with others the same age $(\%)$} \\
\hline Much better & 4.2 & \\
\hline Better & 39.6 & \\
\hline About the same & 56.2 & \\
\hline \multicolumn{3}{|c|}{ Self-perceived memory compared with 5 years ago (\%) } \\
\hline Much better & 2.0 & \\
\hline Better & 4.2 & \\
\hline About the same & 62.5 & \\
\hline Worse & 31.3 & \\
\hline Fall reported in the previous 12 months $(n)$ & 12.0 & \\
\hline Falls in previous 12 months (mean \pm SD) & $0.4 \pm 1.0$ & $0-2$ \\
\hline Falls requiring medical treatment $($ mean \pm SD) & $0.5 \pm 0.5$ & $0-1$ \\
\hline \multicolumn{3}{|l|}{ Marital status $(\%)$} \\
\hline Married & 52.1 & \\
\hline Widowed & 33.3 & \\
\hline Divorced & 4.2 & \\
\hline Single-never married & 10.4 & \\
\hline \multicolumn{3}{|l|}{ Highest level of education (\%) } \\
\hline Some elementary or high school & 8.3 & \\
\hline High school diploma & 16.7 & \\
\hline Some postsecondary & 18.7 & \\
\hline Postsecondary diploma & 56.3 & \\
\hline \multicolumn{3}{|l|}{ Finances at the end of the month $(\%)$} \\
\hline Usually have money left over & 81.3 & \\
\hline Just enough to make ends meet & 16.7 & \\
\hline Refused to respond & 2.0 & \\
\hline
\end{tabular}

Note: $\mathrm{VO}_{2 \text { max }}$, maximal oxygen consumption (a measure of cardiorespiratory fitness).

were log-transformed, substantially improving the normality of the PA counts. To prevent 0 values from being treated as missing, 1 was added to each value. Figure 1 represents a histogram and boxplot for the log-transformed accelerometer counts. Both raw and log-transformed accelerometer counts accumulated across various temperature ranges are presented in Table 3.

Table 4 presents raw and cleaned PA accelerometer data. Raw data include hourly averages of PA counts, including time when accelerometer was not worn. Most PA (62\%) was completed below temperatures of $25{ }^{\circ} \mathrm{C}$ for both raw and cleaned values. PA peaked at approximately $20^{\circ} \mathrm{C}$, and declined as temperatures continued to climb. Despite temperatures increasing above $20{ }^{\circ} \mathrm{C}$, subjects did not completely eliminate PA; however, PA was substantially reduced when ambient temperatures rose above $30{ }^{\circ} \mathrm{C}$.

Age and estimated $V \mathrm{O}_{2}$ max were associated with PA ( $r=-0.35$ and $r=0.40$, respectively; $p<0.01$ ). All weather variables, age, sex, and estimated $V \mathrm{O}_{2}$ max were included in the final multiple linear regression model. Following analy- 
Fig. 1. Histogram and boxplot of log-transformed accelerometer counts.

\begin{tabular}{|c|c|c|}
\hline Histogram & \# & Boxplot \\
\hline $8.75+*$ & 3 & 0 \\
\hline * & 10 & 0 \\
\hline .*** & 44 & 0 \\
\hline.$* * * * *$ & 97 & I \\
\hline$* * * * * * * *$ & 152 & I \\
\hline$* * * * * * * * * * * * * * * * * *$ & 347 & I \\
\hline$* * * * * * * * * * * * * * * * * * * * * * * * * * * * * * * * * * *$ & 664 & +-----+ \\
\hline ***************************************************) & 934 & $1 \quad 1$ \\
\hline$* * * * * * * * * * * * * * * * * * * * * * * * * * * * * * * * * * * * * * * * * * * * * * * * *$ & 915 & $*_{---+-} *$ \\
\hline$* * * * * * * * * * * * * * * * * * * * * * * * * * * * * * * * * * * * * * * * *$ & 744 & I 1 \\
\hline$* * * * * * * * * * * * * * * * * * * * * * * * * * * *$ & 517 & +----+ \\
\hline$* * * * * * * * * * * * * * *$ & 287 & I \\
\hline$* * * * * * * * * *$ & 183 & I \\
\hline$* * * * * * * *$ & 147 & I \\
\hline$* * * *$ & 65 & 0 \\
\hline .** & 33 & 0 \\
\hline.$* *$ & 21 & 0 \\
\hline $0.25+* * *$ & 52 & 0 \\
\hline
\end{tabular}

Table 3. Accelerometer counts recorded across temperature ranges $(n=48)$.

\begin{tabular}{lllllll}
\hline \multirow{2}{*}{ Temperature $\left({ }^{\circ} \mathrm{C}\right)$} \\
\cline { 2 - 7 } Accelerometer counts & $\leq 10$ & $>10-15$ & $>15-20$ & $>20-25$ & $>25-30$ & $\geq 30$ \\
\hline No. of observations & 13 & 264 & 1037 & 2162 & 1521 & 192 \\
Mean & 356.9 & 273.7 & 258.0 & 220.5 & 192.8 & 142.6 \\
Median & 142.8 & 133.9 & 120.5 & 117.0 & 135.3 & 95.6 \\
Mean $(\log )$ & 4.27 & 4.70 & 4.71 & 4.67 & 4.73 & 4.41 \\
Median $(\log )$ & 4.97 & 4.90 & 4.80 & 4.77 & 4.91 & 4.57 \\
\hline
\end{tabular}

Table 4. Raw and cleaned PA values between 0700 and 1900 hours vs. temperature ( $n=$ 48).

\begin{tabular}{lllll}
\hline Temperature & $\begin{array}{l}\text { Mean PA } \\
\text { raw data }\end{array}$ & $\begin{array}{l}\text { \% change } \\
\text { from }<20{ }^{\circ} \mathrm{C}\end{array}$ & $\begin{array}{l}\text { Mean PA } \\
\text { cleaned data }\end{array}$ & $\begin{array}{l}\% \text { change } \\
\text { from }<20{ }^{\circ} \mathrm{C}\end{array}$ \\
\hline All $(n=936)$ & $195.1 \pm 152.4$ & - & $231.5 \pm 182.7$ & - \\
$<20{ }^{\circ} \mathrm{C}$ & $208.1 \pm 171.9$ & - & $274.3 \pm 234.3$ & - \\
$21-25{ }^{\circ} \mathrm{C}$ & $200.3 \pm 161.0$ & $\downarrow 4.0 \%$ & $242.8 \pm 186.3$ & $\downarrow 11.5 \%$ \\
$26-30{ }^{\circ} \mathrm{C}$ & $180.5 \pm 110.1$ & $\downarrow 13.3 \%$ & $201.4 \pm 133.9$ & $\downarrow 26.8 \%$ \\
$\geq 31{ }^{\circ} \mathrm{C}$ & $110.5 \pm 79.3$ & $\downarrow 46.9 \%$ & $141.1 \pm 99.8$ & $\downarrow 48.6 \%$ \\
Humidex $28{ }^{\circ} \mathrm{C}$ & $183.6 \pm 133.8$ & - & $209.8 \pm 154.8$ & - \\
\hline
\end{tabular}

\footnotetext{
Note: PA, physical activity, displayed as hourly average counts $\cdot \mathrm{min}^{-1} \pm \mathrm{SD}$ ); $\%$ change calculated
} as $\left(\frac{\text { average hourly counts } \min ^{-1}}{\min \text { of PA }}-\frac{\text { new temperature range average PA }}{\text { temperature range average PA }<20{ }^{\circ} \mathrm{C}} \times 100\right)+1$.

sis, only age and Air Quality Index remained significant in the linear mixed effects model. To examine the interaction of temperature with estimated $V \mathrm{O}_{2}$ max , the terms extreme $\times$ $\mathrm{VO}_{2} \max$ (signifying extreme temperatures of $>30{ }^{\circ} \mathrm{C}$ ), Temp $\times V \mathrm{O}_{2 \max }$, and Temp ${ }^{2} \times V \mathrm{O}_{2 \max }$ were used (Table 5) .

The distribution of age and sex across estimated $V \mathrm{O}_{2} \max$ tertiles is illustrated in Table 6. Although differences between fitness tertiles and average PA with corresponding temperature were apparent (Fig. 2), estimated $\mathrm{VO}_{2} \max$ was not a significant variable in the multiple linear regression model, when combined with extreme temperatures $(p=0.12)$, suggesting that, in this sample population, fitness provided no advantage toward PA accumulation as temperatures rose.

\section{Discussion}

The results reported in Table 3 indicate that PA levels appear to be fairly constant until temperatures reach $30{ }^{\circ} \mathrm{C}$, at which time they decrease rapidly. At lower temperatures, the mean of the log is lower, but the median counts are actually greater than at other temperatures; however, this is based on only 13 observations. These results were similar to the curvilinear relationship reported by Togo and colleagues (2005), in which PA (i.e., pedometer steps.day ${ }^{-1}$ ) declined as daytime temperatures increased. Yasunaga and colleagues (2008) commented that older adults primarily accumulate low intensity PA ( $<3$ METs) during the summer months, 
Fig. 2. Average cleaned physical activity $(\mathrm{PA})$ and temperature recorded across estimated maximal oxygen consumption $\left(V \mathrm{O}_{2}\right.$ max $)$ tertiles. Temperature refers to the average temperature recorded between 0700 hours and 1900 hours for participants within each tertile. *, $p<0.05$.

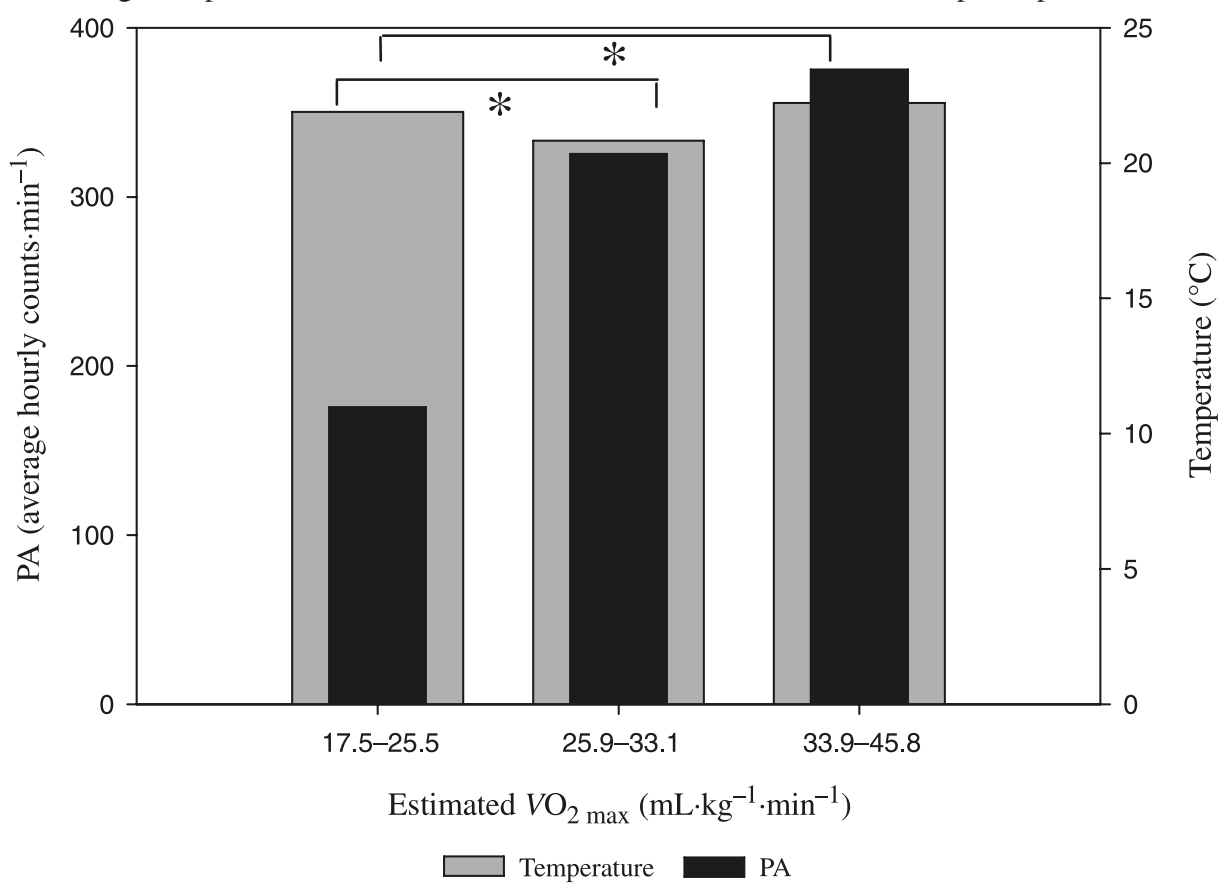

Table 5. Mixed regression models to evaluate the effect of temperature.

\begin{tabular}{lc}
\hline Model & $p$ value \\
\hline Model 1 & \\
$\quad$ Temperature (continuous) & 0.193 \\
Model 2 & \\
$\quad$ Temperature & 0.025 \\
$\quad$ Temperature & 0.038 \\
Model 3 & \\
$\quad$ Hot $\left(>30{ }^{\circ} \mathrm{C}\right.$ vs. $\left.\leq 30{ }^{\circ} \mathrm{C}\right)$ & 0.095 \\
Model 4 & \\
$\quad$ Extreme vs. normal $\left(<10{ }^{\circ} \mathrm{C}\right.$ or $>30{ }^{\circ} \mathrm{C}$ vs. $\geq 10{ }^{\circ} \mathrm{C}$ and & 0.042 \\
$\left.\quad \leq 30{ }^{\circ} \mathrm{C}\right)$ & \\
\hline
\end{tabular}

and there was very little accumulation of moderate to high intensity PA (>3 METs) during these summer months. Alternately, Chan et al. (2006) reported that rising temperatures positively influenced PA. These authors suggested that any rise in temperature of $10{ }^{\circ} \mathrm{C}$ or more during the month was associated with increased PA (i.e., accumulated steps.day ${ }^{-1}$ ). It is important to note that hot and humid weather conditions were not evident in the study by Chan et al. (2006).

Estimated $V_{2} \mathrm{O}_{2}$ max a variable not considered in previous weather and PA studies. The results of this study suggest that participants who had better fitness (higher estimated $V \mathrm{O}_{2}$ max values within the second and third tertile) were no more likely to be active or nonactive, despite higher temperatures (above $30{ }^{\circ} \mathrm{C}$ ), than less fit individuals. This was likely due to the indoor environment that all participants exercised in, lessening the potential influence of outdoor temperature on their ability to perform moderate to vigorous PA. A previous report, using pedometer assessment of ambulatory activity, suggested that the majority of daily accumulated PA in a similar older adult exerciser group
Table 6. Distribution of age and sex across estimated $V \mathrm{O}_{2 \max }$ tertiles $(n=40)$.

\begin{tabular}{lllll}
\hline $\begin{array}{l}\text { Fitness tertile } \\
\left(\mathrm{mL} \cdot \mathrm{kg}^{-1} \cdot \mathrm{min}^{-1}\right)\end{array}$ & $\begin{array}{l}\text { Average } \\
\text { age } \\
(\mathrm{y} \pm \mathrm{SD})\end{array}$ & $\begin{array}{l}\text { Females } \\
(n)\end{array}$ & $\begin{array}{l}\text { Males } \\
(n)\end{array}$ & $\begin{array}{l}\text { Average estimated } \\
V \mathrm{O}_{2 \max }\end{array}$ \\
\hline $1(17.5-25.5)$ & $79.2 \pm 3.9$ & 13 & 0 & $21.5 \pm 2.9$ \\
$2(25.9-33.1)$ & $76.8 \pm 4.9$ & 11 & 3 & $29.7 \pm 2.2$ \\
$3(33.9-45.8)$ & $75.3 \pm 3.5$ & 5 & 8 & $38.8 \pm 3.3$ \\
\hline
\end{tabular}

was achieved through indoor exercise participation (TudorLocke et al. 2002). Alternatively, participants may have exercised at cooler times of the day (morning or night), outside of the analysis time frame of 0700 hours to 1900 hours, and thus PA may not have been effectively recorded. Age- and sex-associated changes in thermal tolerance likely had little effect on PA accumulation, as described by Kenney and Munce (2007). Finally, there were not enough participants sampled during extreme temperatures to truly determine if fitness would facilitate PA participation during hotter temperatures.

Certain limitations of this study must be considered. The study sample was randomly selected from a membership list of exercising older adults, and all study participants were actively exercising 2 or 3 times per week. As such, this sample likely performed regular bouts of moderate to vigorous PA (i.e., exercise classes), more than would normally be observed in a general population of older adults, despite weather conditions. Any observed differences in PA due to weather seen in this sample may be magnified in the general population as a result of greater variance in overall physical fitness and accessibility to exercise facilities, other than outdoor walking. Alternatively, any observed differences in PA may be diminished in a generalized population, given that many older adults accumulate low levels of PA, either in- 
doors or outdoors, regardless of temperature or weather variables (NACA 2006).

Because of the availability of accelerometers, a maximum of 10 participants were able to wear the accelerometer at any given time; therefore, not all participants wore the accelerometer during the same week. As a result, each participant was not subject to the same range of weather conditions during the sampling period, and direct comparison between individual participants was not possible. Nevertheless, each subject wore the accelerometer for 7 days, allowing for collection of PA data across various days of the week (e.g., weekdays and weekend days), thus generating a better representation of an individual's overall activity level. The 7-day assessment period provided an opportunity for each participant to experience a greater range of weather conditions. Finally, while the scheduling of participants to assessment period was not random, it was done in advance, and the results are not biased by volunteer effects based on weather variables. Physical activity may have been underestimated when subjects engaged in water-based activities, as this could not be measured with the accelerometer. Swimming was the most common water-based PA, with a total of 7 subjects indicating they swam between 1 to 8 times during the assessment period for an average of $54.6 \mathrm{~min}$.

Using the Freedson et al. (1998) conversion equation to change counts $\mathrm{min}^{-1}$ into MET values likely provides an underestimation of overall energy expenditure for this population, as the conversion equation was originally developed with a sample of younger adults. Underestimation was observed using data from this sample group of exercising older adults who achieved average hourly PA values that did not exceed the corresponding MET value for light activity (Table 1), despite the fact that the study population was comprised of participants who exercised 2 or 3 times per week. Paterson and colleagues (2007) reported that PA at an intensity of 3-4 METs is considered to be of moderate to vigorous intensity for older adults. Thus, the observed MET values in the current investigation suggest that these older adults were meeting recommended levels for energy expenditure.

There were 3 potential limitations for assessing vigorous PA in this investigation. First, the older subjects may have selectively performed more vigorous ( $>4.5$ METs) PA during cooler times of the day (before 0700 hours or after 1900 hours) to avoid the heat, and thus would have been outside the period monitored for this investigation. Second, PA that required primarily upper-body movement - for example, weight-training performed during each exercise class - was likely underestimated by the waist-borne accelerometer (Montoye et al. 1996; Welk 2005). Finally, the accumulation of vigorous activity was likely lost in the calculation of average hourly counts. $\mathrm{min}^{-1}$. Visual inspection of the data confirms that the majority of exercise bouts lasted less than $30 \mathrm{~min}$. Therefore, $30 \mathrm{~min}$ of vigorous activity would be averaged against $30 \mathrm{~min}$ of light activity, effectively masking the contribution of vigorous activity to the average hourly counts $\cdot \mathrm{min}^{-1}$.

Regional and climate-specific research is required to account for factors of acclimatization (Curriero et al. 2002; Hechler et al. 2004; O’Neill et al. 2005). Future investiga- tions should consider evaluating the influence of wintertime weather on PA participation by older adults. The use of multiple accelerometers (i.e., upper body and lower body) may provide a better estimation of total PA, as waist-borne accelerometers do not accurately record upper-body movements (e.g., weight-lifting exercises). Measurement time periods of less than $1 \mathrm{~h}$ may provide future studies with a better estimation of vigorous activity, as older adults tend to participate in PA at this level for shorter bouts of time. Finally, an assessment of the role of the aging thermoregulatory system and its role in PA tolerance is warranted, considering the biological link between the body's ability to maintain thermal homeostasis and the unavoidable consequence of heat production during vigorous PA.

It is crucial that older adults remain active and exercise regularly to remain functionally independent. Alternatives to outdoor activities are important for members of this population to consider if they plan to continue regular exercise during warmer weather. The influence of weather and temperature should be considered with regard to daily PA reported during summer months. Fitter older adults do not seem to tolerate hotter daytime temperatures any better than their less fit counterparts. Moderate to vigorous activity is advised to engender fitness and maintain existing functional capacity in older adults (Paterson et al. 2007), and doing PA indoors - in a climate-controlled environment - is a plausible solution. Temperature and Air Quality Index are influential factors affecting PA in older adults (70+ years of age). As might be hypothesized, age is also a factor, as older subjects participated in less vigorous PA than their younger counterparts. However, in this investigation, cardiorespiratory fitness had little impact on PA levels recorded, despite changes in ambient temperatures.

\section{Acknowledgments}

Funding for this study was provided through the UWO Academic Development Fund. The authors appreciate the contributions made by the staff and participants at the Canadian Centre for Activity and Aging.

\section{References}

ActiGraph [online]. GT1M technical details. Available from http:// www.theactigraph.com/PDFs/GT1MTechnicalDocumentation. pdf. [Accessed 4 September 2007.]

American College of Sports Medicine (ACSM). 2006. ACSM's guidelines for exercise testing and prescription. 6th ed. Lippincott Williams \& Wilkins, Philadelphia Penn. pp. 3-4.

Anderson, G.S., Meneilly, G.S., and Mekjavic, I.B. 1995. Gender differences in physiological reactions to thermal stress. Eur. J. Appl. Occup. Physiol. 71: 95-101. doi:10.1007/BF00854965. PMID:7588704.

Anderson, G.S., Meneilly, G.S., and Mekjavic, I.B. 1996. Passive temperature liability in the elderly. Eur. J. Appl. Physiol. Occup. Physiol. 73: 278-286. doi:10.1007/BF02425488. PMID: 8781858.

Bischoff-Ferrari, H.A., Orav, J.E., Barrett, J.A., and Baron, J.A. 2007. Effect of seasonality and weather on fracture risk in individuals 65 years and older. Osteoporos. Int. 18: 1225-1233. doi:10.1007/s00198-007-0364-6. PMID:17384897.

Bittel, J.H.M., Nonotte-Varly, C., Livecchi-Gonnot, G.H., Savourey, G.L.M.J., and Hanniquet, A.M. 1988. Physical fitness 
and thermoregulatory reactions in a cold environment in men. J. Appl. Physiol. 65: 1984-1989. PMID:3209545.

Chan, C.B., Ryan, D.A.J., and Tudor-Locke, C. 2006. Relationship between objective measures of physical activity and weather: a longitudinal study. Int. J. Behav. Nutr. Phys. Act. 3: 1-9. doi:10.1186/1479-5868-3-1. PMID:16390544.

Collins, K.J., Exton-Smith, A.N., James, M.H., and Oliver, D.J. 1980. Functional changes in autonomic nervous responses with ageing. Age Ageing, 9: 17-24. doi:10.1093/ageing/9.1.17. PMID:7361632.

Curriero, F.C., Heiner, K.S., Samet, J.M., Zeger, S.L., Strug, L., and Patz, J.A. 2002. Temperature and mortality in 11 cities of the eastern United States. Am. J. Epidemiol. 115: 80-87. PMID:11772788.

Diaz, J., Garcia, R., Velazquez de Castro, F., Hernandez, E., Lopez, C., and Otero, A. 2002. Effects of extremely hot days on people older than 65 years in Seville (Spain) from 1986 to 1997. Int. J. Biometeorol. 46: 145-149. doi:10.1007/s00484002-0129-z. PMID:12194008.

Dufour, A., and Candas, V. 2007. Ageing and thermal responses during passive heat exposure: sweating and sensory aspects. Eur. J. Appl. Physiol. 100: 19-26. doi:10.1007/s00421-0070396-9. PMID:17242944.

Environment Canada. 2006. National climate archive. [Online.] Available from http://climate.weatheroffice.ec.gc.ca/climateData/ canada_e.html. [Accessed 10 August 2006.]

Environment Canada. 2007. Temperature and precipitation in historical perspective. [Online] Accessed from http://www.msc.ec. gc.ca/ccrm/bulletin/summer06/national_e.cfm. [Accessed 5 April 2008.]

Foster, K.G., Ellis, F.P., Dore, C., Exton-Smith, A.N., and Weiner, J.S. 1976. Sweat response in the aged. Age Ageing, 5: 91-101. doi:10.1093/ageing/5.2.91. PMID:1274803.

Freedson, P.S., Melanson, E., and Sirard, J. 1998. Calibration of the Computer Science and Applications, Inc. accelerometer. Med. Sci. Sports Exerc. 30: 777-781. doi:10.1097/00005768199805000-00021. PMID:9588623.

Gulli, G., Cevese, A., Cappelletto, P., Gasparini, G., and Schena, F. 2003. Moderate aerobic training improves autonomic cardiovascular control in older women. Clin. Auton. Res. 13: 196-202. PMID:12822041.

Health Canada. 1999. Canada's physical activity guide to healthy active living for older adults - handbook. [Online.] Available from http://www.phac-aspc.gc.ca/pau-uap/fitness/pdf/ guide_handbook_older.pdf. [Accessed 14 August 2007.]

Hechler, T., Chau, J.Y., Giesecke, S., and Vocks, S. 2004. Perception of seasonal changes in physical activity among Australian and German women. Med. J. Aust. 181: 710-711. PMID: 15588218.

Heiat, A., Vaccarino, V., and Krumholz, H.M. 2001. An evidencebased assessment of federal guidelines for overweight and obesity as they apply to elderly persons. Arch. Intern. Med. 161: 1194-1203. doi:10.1001/archinte.161.9.1194. PMID:11343442.

Ho, C.W., Beard, J.L., Farrell, P.A., Minson, C.T., and Kenney, W.L. 1997. Age, fitness, and regional blood flow during exercise in the heat. J. Appl. Physiol. 82: 1126-1135. PMID:9104849.

Kenney, W.L., and Munce, T.A. 2007. Invited review: aging and human temperature regulation. J. Appl. Physiol. 95: 2598-2603.

Lee, I.M., and Paffenbarger, R.S., Jr. 2000. Associations of light, moderate, and vigorous intensity physical activity with longevity. The Harvard Alumni Health Study. Am. J. Epidemiol. 151: 293-299. PMID:10670554.

Ma, Y., Olendzki, B.C., Li, W., Hafner, A.R., Chiriboga, D.,
Hebert, J.R., et al. 2006. Seasonal variation in food intake, physical activity, and body weight in a predominantly overweight population. Eur. J. Clin. Nutr. 60: 519-528. doi:10.1038/sj.ejen. 1602346. PMID:16340952.

Mancuso, C.A., Sayles, W., Robbins, L., Phillips, E.G., Ravenell, K., Duffy, C., et al. 2006. Barriers and facilitators to healthy physical activity in asthma patients. J. Asthma, 43: 137-143. doi:10.1080/02770900500498584. PMID:16517430.

Marion, G.S., McGann, K.P., and Camp, D.L. 1989. Core temperature in the elderly and factors which influence its measurement. Gerontology, 37: 225-232.

Matthews, C.E., Freedson, P.S., Hebert, J.R., Stanek, E.J., Merriam, P.A., Rosal, M.C., et al. 2001. Seasonal variation in household, occupational, and leisure time physical activity: longitudinal analysis from the Seasonal Variation of Blood Cholesterol study. Am. J. Epidemiol. 153: 172-183. doi:10.1093/aje/153.2.172. PMID:11159163.

Merrill, R.M., Shields, E.C., White, J.L., and Druce, D. 2005. Climate conditions and physical activity in the United States. Am. J. Health Behav. 29: 371-381. PMID:16006234.

Mirchandani, S., Aharonoff, G.B., Hiebert, R., Capla, E.L., Zuckerman, J.D., and Koval, K.J. 2005. The effects of weather and seasonality on hip fracture incidence in older adults. Orthopedics, 28: 149-155. PMID:15751369.

Montoye, H.J., Kemper, H.C.G., Saris, W.H.M., and Washburn, R.A. 1996. Measuring physical activity and energy expenditure. Human Kinetics Publishers, Champaign, Ill.

NACA. 2006. Seniors in Canada 2006 Report Card (Cat. No. HP30-1/2006E). National Advisory Council on Aging (NACA). Ottawa, Ont.

Nakamura, K., Tanaka, M., Motohashi, Y., and Maeda, A. 1997. Oral temperature of the elderly in nursing homes in summer and winter in relation to activities of daily living. Int. J. Biometeorol. 40: 103-106. doi:10.1007/s004840050027. PMID: 9140212.

O’Neill, M.S., Hajat, S., Zanobetty, A., Ramirez-Anguilar, M., and Schwartz, J. 2005. Impact of control for air pollution and respiratory epidemics on the estimated association of temperature and daily mortality. Int. J. Biometeorol. 50: 121-129. doi:10. 1007/s00484-005-0269-z. PMID:15912362.

Paterson, D.H., Jones, G.R., and Rice, C.L. 2007. Ageing and physical activity: Evidence to develop exercise recommendations for older adults. Can. J. Public Health, 98: S69-S108. PMID: 18213941.

Pedersen, B.K., and Saltin, B. 2006. Evidence for prescribing exercise as a therapy in chronic disease. Scand. J. Med. Sci. Sports, 16(Suppl 1):3-63. doi:10.1111/j.1600-0838.2006.00520.x. PMID:16451303.

Petrella, R.J., Koval, J.J., Cunningham, D.A., and Paterson, D.H. 2001. A self-paced step test to predict aerobic fitness in older adults in the primary care practice. J. Am. Geriatr. Soc. 49: 632-638. doi:10.1046/j.1532-5415.2001.49124.x. PMID: 11380757.

Pivarnik, J.M., Reeves, M.J., and Rafferty, A.P. 2003. Seasonal variation in adult leisure-time physical activity. Med. Sci. Sports Exerc. 35: 1004-1008. doi:10.1249/01.MSS.0000069747.55950. B1. PMID: 12783049.

Potkanowicz, E.S., Caine-Bish, N., Otterstetter, R., and Glickman, E.L. 2003. Age effects on thermal, metabolic, and perceptual responses to acute cold exposure. Aviat. Space Environ. Med. 74: 1157-1162. PMID:14620472.

Richardson, D., and Shepherd, S. 1991. The cutaneous microcirculation of the forearm in young and old subjects. Microvasc. Res. 41: 84-91. doi:10.1016/0026-2862(91)90010-9. PMID:2051956. 
Scremin, G., and Kenney, W.L. 2004. Aging and the skin blood flow response to the unloading of baroreceptors during heat and cold stress. J. Appl. Physiol. 96: 1019-1025. doi:10.1152/ japplphysiol.00928.2003. PMID:14594858.

Smoyer, K.E., Rainham, D.G.C., and Hewko, J.N. 2000. Heatstress related mortality in five cities in Southern Ontario: 19801996. Int. J. Biometeorol. 44: 190-197. doi:10.1007/ s004840000070. PMID:11131291.

Togo, F., Watanabe, E., Park, H., Shephard, R.J., and Aoyagi, Y. 2005. Meteorology and the physical activity of the elderly: the Nakanojo study. Int. J. Biometeorol. 50: 83-89. doi:10.1007/ s00484-005-0277-z. PMID:16044348.

Tu, W., Stump, T.E., Damush, T.M., and Clark, D.O. 2004. The effects of health and environment on exercise-class participation in older, urban women. J. Aging Phys. Act. 12: 480-496. PMID:15851821.

Tucker, P., and Gilliland, J. 2007. The effect of season and weather on physical activity: a systematic review. Public Health, 121: 909-922. doi:10.1016/j.puhe.2007.04.009. PMID:17920646.

Tudor-Locke, C., Jones, G.R., Myers, A.M., Paterson, D.H., and Ecclestone, N.A. 2002. Contribution of structured exercise class participation and informal walking for exercise to daily physical activity in community-dwelling older adults. Res. Q. Exerc. Sport, 73: 350-356. PMID:12230344.

Walter, S.D., Eliasziw, M., and Donner, A. 1998. Sample size and optimal designs for reliability studies. Stat. Med. 17: 101110. doi:10.1002/(SICI)1097-0258(19980115)17:1<101::AIDSIM727>3.0.CO;2-E. PMID:9463853.
Ward, D.S., Evenson, K.R., Vaughn, A., Brown Rogers, A., and Troiano, R.P. 2005. Accelerometer use in physical activity: best practices and research recommendations. Med. Sci. Sports Exerc. 37: S582-S588. doi:10.1249/01.mss.0000185292.71933.91. PMID:16294121.

Welk, G.J. 2005. Principals of design and analyses for the calibration of accelerometry-based activity monitors. Med. Sci. Sports Exerc. 37: S501-S511. doi:10.1249/01.mss.0000185660.38335. de. PMID:16294113.

Westhoff, T.H., Franke, N., Schmidt, S., Vallbracht-Israng, K., Meissner, R., Yildirim, H., et al. 2007. Too old to benefit from sports? The cardiovascular effect of exercise training in elderly subjects treaded for isolated systolic hypertension. Kidney Blood Press. Res. 30: 240-247. doi:10.1159/000104093. PMID 17575470.

Worfolk, J.B. 1997. Keeping frail elders warm: the thermal instabilities of the old have not received sufficient attention in basic educational programs. Geriatr. Nurs. 18: 7-11. doi:10.1016/ S0197-4572(97)90123-3. PMID:9060263.

World Health Organization. 2000. Obesity: preventing and managing the global epidemic. Report of a WHO Consultation on Obesity. WHO, Geneva. p. 9.

Yasunaga, A., Togo, F., Watanabe, E., Park, E., Park, S., Shephard, R.J., et al. 2008. Sex, age, season, and habitual physical activity in older Japanese: the Nakanojo study. J. Aging Phys. Act. 16: 3-13. PMID:18212390. 